\title{
Effect of Mutagens on Frequency and Spectrum of Viable Mutations in Horsegram (Macrotyloma uniflorum (Lam.) Verdc)
}

\author{
Bolbhat S. N. ${ }^{1}$, Gawade. B. B. ${ }^{2}$, Bhoge V. D. ${ }^{2}$, Wadavkar D. S. ${ }^{2}$, \\ Shendage V. $\mathrm{S}^{2}$. and Dhumal K. N. ${ }^{3}$ \\ $1 \& 2$ Department of Botany, Dada Patil Mahavidyalaya Karjat, Dist-Ahmednagar-414402 (M.S.), India \\ ${ }^{3}$ Department of Botany, University of Pune, Pune-411007 (M.S.) India
}

\begin{abstract}
The seeds of horsegram (Macrotyloma uniflorum (Lam.) Verdc) cv. Dapoli Kulthi- 1 were subjected to gamma radiation (100, 200, 300 and 400Gy), EMS (0.2, 0.3, 0.4 and 0.5\%) and combination treatments. The mutations affecting gross morphological changes in plant habit, leaf and pod morphology, and maturity were scored as viable mutations. These mutants were characterized and named on the basis of specific characters constantly observed in them throughout the course of investigation. Effect of mutagens on the frequency and spectrum of different types of viable mutations in $M_{2}$ generation were recorded. The high frequency of mutations in terms of mutants per $1000 \mathrm{M}_{2}$ plant population was observed in low doses of EMS $(0.2 \%)$, gamma radiation (100Gy) as well as in their combination $(400 G y+0.4 \%$ EMS). The range of viable mutations in gamma radiation, EMS and their combinations was 0.61 to $2.16 \%, 0.62$ to $2.98 \%$ and 0.21 to $1.81 \%$ respectively. Spectrum of viable mutations included desirable characters like early maturity, tall and dwarf habit, profuse branching, increased leaf area, higher number of pods, grains and grain weight were used to select desirable mutants.
\end{abstract}

Key words: Horsegram, EMS, Gamma radiation, frequency, viable mutations.

\section{INTRODUCTION}

Horsegram (Macrotyloma uniflorum) is an important pulse crop being cultivated in Indian subcontinent under different environmental conditions ranging from tropical to sub-temperate and is most resistant to biotic and abiotic stresses. It is essentially adapted to dry areas and poor soils but will also respond to extra moisture [1]. Since it is a hardy drought resistant plant, it has been cultivated as a low input agricultural crop of the marginal lands. Large numbers of poor farmers sow horsegram in small areas during the month of November [2]. It is one of the important early domesticated and enriched nutritious crops cultivated mainly in hot dry and tropical countries in a post-rainy season, where the seeds are parched and then eaten after boiling or frying, either whole or as a meal. Legume improvement by conventional breeding methods has limitations mainly due to the insects-pests interference, for which no source of resistance is available [3]. The yield of this crop is far from satisfactory with a range of $250-300 \mathrm{~kg} \mathrm{ha}^{-}{ }^{1}$ comparing with the average yield of $500 \mathrm{~kg}$ ha- 1 in the national scene. Selection of low yielding local cultivars with malnutrition in many cases and seldom nutrition in few cases in association with the inherent soil constraints assumes greater significance for such poor yield and returns in horsegram [4]. Amongst pulses horsegram (Macrotyloma uniflorum (Lam.) Verdc) is highly neglected crop throughout the world and hence require more emphasis on its improvement as it has nutritional and medicinal value too [5]. Induced mutation is one of the best alternatives for the improvement of horsegram as it can help to regenerate and restore the variability, which is generally lost in the process of adaptation to various stresses. Genetic variability is the most essential prerequisite for any successful crop improvement programme as it rovides spectrum of variants for the effective selection, which can be achieved through the processes of hybridization, recombination, mutation and selection [6].

\section{MATERIAL AND METHODS}

The authentic seeds of horsegram (Macrotyloma uniflorum (Lam.) Verdc) cultivar Dapoli Kulthi-1 were procured from Head, Department of Botany, College of Agriculture, Dr. Balasaheb Savant Konkan Krishi Vidyapeeth, Dapoli, Dist-Ratnagiri (M.S.) India. Gamma rays, ethyl methane sulphonate (EMS) and their combinations were employed in present study for the treatments of seeds of horsegram cv. Dapoli Kulthi-1. Gamma radiation from ${ }^{60} \mathrm{Co}$ source fixed in the gamma cell 200 installed at Bhabha Automic Research Center (BARC), Trombay, Mumbai. (MS) was used in the present work. Healthy, dry and uniform seeds of horsegram cv. Dapoli Kulthi-1 with moisture content of 10-12 \% were treated with 100, 200, 300 and 400Gy. Ethyl methane sulphonate (Sigma chemical Co. Ltd. USA) was used for the seed treatment of horsegram cv. Dapoli Kulthi-1. Various concentrations of EMS $(0.2 \%$ to $0.5 \%)$ were prepared in $0.1 \mathrm{M}$ phosphate buffer pH-7.0. Selected seeds were soaked in distilled water for 10 hours and the wet seeds were treated with different 
concentrations of EMS (such as 0.2, 0.3, 0.4 and $0.5 \% \mathrm{v} / \mathrm{v}$ ) for four hours. For combination treatments the gamma irradiated seeds were treated with different concentrations of EMS. The untreated seeds served as control. For each treatment 675 seeds were used. The seeds treated with various concentrations of EMS were washed thoroughly with tap water for two hours to terminate the reaction of chemical mutagen and to leach out the residual chemicals. The treated seeds (675) from each treatment were used for raising $\mathrm{M}_{1}$ generation in field. Present investigation was carried out at Department of Botany, University of Pune, Pune- 411007 (M.S.). All the experiments were carried out in triplicate following RBD design. The distance between two rows and two plants was $30 \times 15 \mathrm{~cm}$ and the distance between two adjacent plots was one meter. The seeds of individually harvested $\mathrm{M}_{1}$ plants were sown in the experimental field to raise $\mathrm{M}_{2}$ generation in separate rows during kharif season of the year 2008. $\mathrm{M}_{2}$ plant population was screened for scoring viable mutations in the field. Mutations affecting different morphological characters such as general architecture of the plant, habit, leaf size, shape, pod size and maturity. The spectrum and frequency of viable mutations was calculated.

\section{Statistical Analysis}

The data were summarized as the means of three replicates with standard deviation as the measures of variability. One-way ANOVA test was performed to determine significant differences due to various treatments. Fisher's LSD (Least significant difference) was used as post hoc test to as certain significant differences among treatments at $\mathrm{p}=0.05$. Statistical analysis and graphical data presentations were carried out by using Sigma stat (ver.3.5).

\subsection{Viable Mutations}

\section{RESULTS}

The mutations affecting gross morphological changes in plant habit, leaf and pod morphology, and maturity were scored as viable mutations. These mutants were characterized and named on the basis of specific characters constantly observed in them throughout the course of investigation. Effect of mutagens on the frequency and spectrum of different types of viable mutations in $\mathrm{M}_{2}$ generation is illustrated in Table- $1,2 \& 3 \mathrm{a}$, $\mathrm{b}, \mathrm{c}, \mathrm{d}$.

\subsection{Frequency and spectrum of viable mutations}

The range of viable mutations in gamma radiation, EMS and their combinations (Table- $1,2 \& 3 \mathrm{a}, \mathrm{b}, \mathrm{c}$, d) was 0.61 to $2.16 \%, 0.62$ to $2.98 \%$ and 0.21 to $1.81 \%$ respectively. As compared to gamma radiation, EMS was more effective to induce viable mutations. The highest percentage of frequency of mutations noted for plant habit, leaf and pod morphology and maturity, due to various treatments of gamma radiation was $0.77 \%, 0.66 \%$, $0.58 \%$ and $0.30 \%$ respectively. These results also indicated that the percentage of plant habit mutations was maximum as compared to others. The highest percentage of mutation frequency of EMS for plant habit, leaf and pod morphology, and maturity was $0.94 \%, 1.07 \%, 0.67 \%$ and $0.30 \%$ respectively. The leaf type mutations were highest in percentage as compared to others. In combination treatments the percentage of frequency for plant habit, leaf, pod and maturity type mutations, was $0.76 \%, 0.63 \%, 0.49 \%$ and $0.28 \%$ respectively.

These results indicated that EMS treatments were more effective than gamma radiation and combination treatments. The highest percentage of mutations was obtained in EMS (2.98\%) and gamma radiation $(2.16 \%)$ as compared to combination treatment $(1.81 \%)$.

The trend noted was: EMS > Gamma radiation > Combination treatments

Wide frequency and spectrum of viable mutations was observed in horsegram cv. Dapoli Kulthi-1 in $\mathrm{M}_{2}$ generation due to treatments of GR, EMS and GR + EMS in different doses/ concs. Several researchers have attributed the differences in frequency and spectrum of viable mutations to genetic differences in the cultivars [7, 8, and 9]. Multiple mutations were due to mutations in pleotropic gene, gene clusters, or loss of chromosomal segments [10]. In the present investigation, the spectrum and frequency of viable mutations were recorded. This could be due to differential mode of action of the mutagens on different base sequences in various genes. The results of present study have also indicated that horsegram cv. Dapoli Kulthi-1 was highly sensitive to mutagenic treatments. The differential frequency and spectrum of viable mutations might be due to the individual impact of the mutagen and its dose/ concs. employed for the treatments.

\subsection{Types of viable mutations}

3.3.1. Plant habit mutants

Gigas: These mutants were vigorous, upright and tall with larger, thick, close pinnae and thick profuse branching at the base. Pods were large containing bold seeds. Gamma radiation treatments 100, 200 and 300Gy, EMS $0.2 \%$ and $0.5 \%$ and various combination treatments had induced these mutants.

Tall: These mutants were vigorous, tall, with medium and thick leaves, normal flowers and pods. Gamma radiation 100 and 300 Gy, EMS $0.2 \%$ and $0.5 \%$ and various combination treatments had induced these mutants. 
Dwarf: Plant height of these mutants ranged from 15 to $20 \mathrm{~cm}$ and had profuse branching at the base which formed a dense umbrella like canopy. This mutation was observed in all treatments of gamma radiation, EMS and their combinations.

Compact: These mutants were characterized with dwarf, profuse and compact branches. The branching was more at the base, giving rise to dense, interwoven secondary branches, which ultimately made the mutant compact. This mutation was observed in all gamma radiation treatments, EMS $(0.2 \%$ and $0.5 \%)$, and in different combination treatments.

Bouquet: These mutants had profuse branching at the base, which remained very close to each other forming a bunch. The canopy of secondary branches and leaves together gave an appearance of bouquet. This mutant was observed only in EMS $(0.2 \%$ and $0.5 \%)$ and in combination treatments but not in gamma radiation.

Erect: The mutant was erect and tall with shy branching and light green pinnae. This mutation was observed in 100 and $300 \mathrm{~Gy}$, EMS $(0.2 \%$ and $0.5 \%)$ and in various combination treatments. The highest frequency was recorded at $100 \mathrm{~Gy}+0.2 \% \mathrm{EMS}(0.19 \%)$.

Tendrilar: These types of mutants were very weak, slender, branched or unbranched with very few leaflets. The distal portion of stem was tendrilar and had twining tendency. These were isolated in 200Gy, $0.3 \%$ EMS and in different combination treatments. The highest frequency was recorded at 300Gy $+0.5 \%$ EMS $(0.14 \%)$.

Spreading: These mutants were creeping on the ground with terminal branches (30 to $60 \mathrm{~cm}$ length). They were induced by all gamma radiation, EMS and combination treatments. The highest frequency of these mutants was recorded in $200 \mathrm{~Gy}+0.4 \% \mathrm{EMS}(0.14 \%)$.

Tall and gigas mutants obtained in the present investigation showed vigorous growth and pods with bold seeds. Similar types of mutants were reported in chickpea $[11,12,13]$. Increase in plant height was due to the changes in the internodal length [14] and increase in cell number and cell length or both [15]. In blackgram $[16,17,18]$, in soybean [19] reported tall and gigas mutants with the treatments of physical as well as chemical mutagens.

Bouquet, dwarf, bushy, spreading and erect mutants in chickpea were induced due to gamma rays and EMS [7]. In mungbean tall, dwarf, compact and spreading mutants induced with SA, EMS and gamma radiation [20]. Different types of viable mutants were observed in soybean variety MACS 450 with GR and EMS treatments [21]. He recorded various viable mutations such as plant height mutants (stunted, dwarf, semi dwarf, tall, very tall and giant). Stunted or miniature dwarf, dwarf, semi dwarf mutants, were found in all combination treatments of GR + EMS. Spreading and semi spreading mutants were reported in mothbean [22]. Erect and unbranched mutants induced in blackgram with gamma rays [18].

\subsubsection{Leaf mutants}

Plants with remarkable variations in size, shape and arrangement of leaflets were observed in $\mathrm{M}_{2}$ progeny. They were broadly classified in to ten categories.

Super gigas : These mutants had extremely large, thick, dark green leaflets with very prominent midrib, thick and semi erect stem and sparse branching. This type of mutation was observed with high frequency in $0.3 \%$ EMS $(0.27 \%)$ and also in treatments like $0.2 \%$ EMS, 100Gy $+0.2 \%$ EMS, 300Gy $+0.5 \%$ EMS.

Gigas: Mutants were vigorous, upright tall with large thick pinnae, profuse branching. Pods were large with bold seeds. This type of mutation was observed with high frequency in 200Gy $(0.23 \%)$. They were also recorded in EMS and combination treatments.

Broad: These mutants were vigorous, upright, dwarf with large, thick, close pinnae. Highest frequency of this type was noted as $0.14 \%$ in $0.3 \%$ EMS and combination treatments.

Narrow: Mutants had arrow like long leaflets, tapering towards the tip. Highest frequency $(0.20 \%)$ of this type was noted in $0.2 \%$ EMS. These mutants were also recorded in gamma radiation, EMS and combination treatments.

Small: These mutants were associated with dwarfness, small leaflets and light green colour with profuse branching at the base. Highest frequency $(0.28 \%)$ was recorded in $400 \mathrm{~Gy}+0.4 \%$ EMS. Gamma radiation, EMS and their combinations also induced such type of mutation.

Tiny: This mutant had minute, needle like sessile leaf. Plants were dwarf with light yellowish-green colour leaves. This type of mutation was observed with high frequency in $0.3 \% \mathrm{EMS}(0.07 \%)$. It was also recorded in $100 \mathrm{~Gy}+0.4 \% \mathrm{EMS}, 200 \mathrm{~Gy}+0.2 \% \mathrm{EMS}$ and 400Gy + 0.3\%EMS.

Stalked: This mutant had long stalked petiole in each pinnae. The pinnae were smaller and light green. This type of mutation was observed in 300 and 400Gy.

Close pinnae: These mutants were having very close pinnae on rachis. The plants were dwarf with thick stem. Pods were longer and narrow. It was observed in maximum treatments of gamma radiation, EMS and their combinations. The high frequency $(0.14 \%)$ was noted in $0.3 \%$ EMS.

Curly: This mutant had curly leaflets with elongated petiole. The leaflets were wedge shaped with shorter leaf lamina, curling towards centre. The plants were erect with pale green foliage. This mutation was 
observed in all gamma radiation, EMS $(0.2 \%$ and $0.3 \%)$, and various combination treatments. Highest frequency $(0.18 \%)$ of this mutation was observed in 400Gy treatment.

Long: Such mutants were dwarf having narrow and very long leaflets. This type of mutation was observed in EMS $(0.2 \%, 0.3 \%$ and $0.5 \%)$, and different combination treatments. Highest frequency $0.14 \%$ was observed in $400 \mathrm{~Gy}+0.5 \% \mathrm{EMS}$.

Different types of leaf mutations such as super gigas, gigas, broad, narrow, small, tiny, stalked, close pinnae, curly and long were observed in $\mathrm{M}_{2}$ generation of horsegram with GR, EMS and GR +EMS treatments. Leathery, narrow, small, broad, ovate and lobed leaf mutants were noted in Vigna [23]. Leaf mutants like small and linear were recorded in blackgram [24] while broad and small, round, narrow, curly and thick leaf mutants were reported in soybean $[9,19]$. Morphological mutations in cowpea such as tendrilar and broad leaflet were observed [25]. Small, long, long apex, triangular and broad leaf mutants were recorded in blackgram[18]. Gigas, compact and curly leaf mutants were isolated in chickpea [13]. Narrow, small, curly and hairy leaf mutants were noted in groundnut [26]. Small, long and narrow leaflet mutants were isolated in rajmash [27]. Curly leaf mutants were also reported in mungbean [10]. The changes in shapes of the leaves were due to chromosomal aberrations, induced by chemical mutagens and ionizing radiation.

The leaf mutations obtained in horsegram may be ascribed to above cited reasons, which may be useful as gene markers in conventional breeding. These may be useful for understanding the genetic control of leaf formation and regulation of their size, shape and form.

\subsubsection{Maturity mutants}

Early: These mutants were associated with dwarfness and showing early flowering within a short span of 30-33 days in comparison with the flowering duration of 53-57 days in control. The total duration of the crop in such mutant was 65-70 days against 100-110 days in control. This type of mutation was observed with high frequency $(0.28 \%)$ in $400 \mathrm{~Gy}+0.5 \% \mathrm{EMS}$. These mutants were induced by $300 \mathrm{~Gy}, 0.2 \% \mathrm{EMS}$ and various combination treatments.

Late: These mutants were with broad and thick dark green coloured foliage, tall and bearing late flowers as compare to control. Flowering in these mutants was achieved in 60 to 65 DAS against 53 to 57 DAS in control. The total duration of the crop in such mutant was 115-120 DAS against 100-110 DAS in control. This mutation was observed in near about fifty to sixty percent treatments of gamma radiation, EMS and their combinations.

The early mutants were recorded in $\mathrm{M}_{2}$ with GR, EMS, and their combinations. These mutants showed rapid growth and early maturity. Several workers like [28 \& 29, 22, 30, 31, 7, 32, 33, 19, $21 \& 34]$ reported early mutants in horsegram, mothbean, winged bean, blackgram, lentil, cowpea, chickpea, urdbean and soybean respectively.

In present investigation the early mutants of horsegram show pod maturity within 60-65 DAS in the gamma radiation, EMS and combination treatments. The agronomic traits like early flowering and pod maturity have bean always given paramount importance, while planning the breeding strategies. The early mutants could be very much useful for genecological studies [35]. The earliness is mainly achieved through rapid growth, during early stages of ontogeny and initiation of first inflorescence. Early maturity in the mutants may be to the physiological, biochemical, enzymological and hormonal changes induced by the mutagens.

The late mutants were noted in $\mathrm{M}_{2}$ generation of horsegram with gamma radiation, EMS, and their combinations. Such mutants were reported $[22,27,34,37 \& 20,30$ and 19, 21, 34] in mothbean, rajmash, fababean, mungbean, lentil, soybean respectively. The main reason attributed to the late maturity were inadequate production of flowering hormones, physiological disturbances, enhanced production of a floral inhibitors and reduced ability to respond to the floral stimulus in the shoot apex [38].

Late or early maturity has agronomic significance as these mutants suit for the specific requirement of breeding strategy [39]. The lateness in maturing is worthwhile to prolonging the vegetative phase and allows the development of a strong sink which was a result to enhanced yield. In addition the period from flowering to maturity should also be long enough for better seed filling. The late mutants were noted in horsegram with the treatments of gamma radiation, EMS and their combinations.

\subsubsection{Pod mutants}

Gigas: These mutants were associated with gigas plant type, with very large pods containing 5-6 bold seeds per pod. This mutation was noted in near about fifty to sixty percent treatments of gamma radiation, EMS and their combinations.

Long: The plants were normal in appearance with comparatively much longer pods, containing 7 to 8 seeds per pod. Long pod mutants were recorded in gamma radiation treatments (100 and 300Gy), in EMS (0.2\% and $0.5 \%)$ and in their combination treatments.

Broad: The mutants had broad pods containing 5-6 bold seeds per pod. Broad pod mutants were noted in gamma radiation treatment (100 and 400Gy), EMS (0.2\%, $0.4 \%$ and $0.5 \%)$, and their combination treatments. 
Narrow: These mutants had comparatively narrow pods, with 6-7 small seeds. Such type of mutants were isolated in gamma radiation treatments (100 and 300Gy), EMS (0.2\%, 0.4\% and 0.5\%EMS), in their combinations.

Small: It was associated with dwarf plant type mutation having very small pods containing 2-3 seeds per pod. This type of mutation was recorded in most of the gamma radiation, EMS and combinations treatments.

Pod mutations such as long, large, narrow and small were recorded in $\mathrm{M}_{2}$ generation. Long pod mutants were reported in cluster bean [40], in winged bean [41], in mungbean [42]. In chickpea [7] and in urdbean [34] noted gigas, long large, narrow and elongated pod mutations. Long, narrow, bold, beaded and hairy pod mutants were isolated in urdbean [43]. Smooth and short pod mutants were reported in Vigna [23]. Big, small and short pod mutants [44 \& 45] isolated in chickpea and blackgram respectively.

\subsubsection{Sterile mutants:}

Sterile mutants were not bearing the flowers and fruits throughout their life. These mutants were recorded in $0.5 \% \mathrm{EMS}$ and their combinations $100 \mathrm{~Gy}+0.2 \% \mathrm{EMS}$.

Sterile mutants were noted in horsegram treated with GR, EMS and GR + EMS. In blackgram, [18 \& 9], in soybean [19, 21, 34], in chickpea and blackgram [44, $13 \& 45]$ noted sterile mutants by using different physical and chemical mutagens. Male sterility results in to malformation of the male reproductive organs caused by gene transformation of stamens into carpel-like organs. Chemical mutagens probably induce sterility due to increased sensitization of the embryo and seeds as a result of presoaking and decreased intrasomatic selection. Male sterility may be attributed to gene mutation or deletion [46].

\subsubsection{High yielding mutants}

These mutants possess high yield contributing characters viz. number of pods, thousand seed weight and total seed yield per plant. High yielding mutants were isolated in $\mathrm{M}_{2}$ generation.

Such type of mutants were recorded earlier in mungbean [20], in chickpea [32], in soybean [19, 21, 34], in urdbean [33] and in grasspea [47].

\section{CONCLUSION}

Lower doses/ concs. of mutagens exhibited higher frequency of viable mutations. Higher frequency of viable mutations was recorded in EMS as compared to gamma rays. All the treatments had induced widest spectrum of viable mutations and the highest frequency was noted in 100Gy, 0.2\% EMS and 400Gy+0.4\%EMS. The viable mutants tall, gigas, bouquet, dwarf, compact, spreading, tendrilar and erect were obtained due to the treatments of GR, EMS and their combinations. More than 10 different types of leaf mutants such as supergigas, gigas, broad, narrow, small, tiny, stalked, close pinnae, curly, long leaf, early and late were recorded. The pod mutants observed were gigas, long, broad, narrow and small.

[1] D. S. Virk, M. Chakraborty, J. Ghosh and D. Harris. Participatory evaluation of horsegram (Macrotyloma uniflorum) varieties and their on-station responses to on-farm seed priming in eastern India. Expl Agric., 42, 2006, 411-425.

[2] A. D. Barnabas, G. K. Radhakrishnan and U. Ramakrishnan. Characterization of a begomovirus causing horsegram yellow mosaic disease in India. Eur. J. Plant Pathol., 127, 2010, 41-51.

[3] C. S. Wang, S. V. Mohamed, J. M. Sung and T. L. Jeng. Optimization of somatic embryogenesis in suspension cultures of horsegram (Macrotyloma uniflorum (Lam.) Verdc) a hardy grain legume. Scientia Horticulturae, 106, 2005, $427-439$.

[4] B. S. Keshava, A. S. Halepyati, B. T. Pujari and B. K. Desai. Yield and economics of horsegram (Macrotyloma uniflorum (Lam.) Verdc) as influenced by genotypes, plant densities and phosphorus levels. Karnataka J. Agric. Sci., 20(3), 2007, 589-591.

[5] S. N. Bolbhat. Studies on induced mutations in horsegram (Macrotyloma uniflorum (Lam.) Verdc). doctoral diss., University of Pune, Pune (MS), India, M.Sc., 2011.

[6] K. N. Dhumal and S. N. Bolbhat. Induction of genetic variability with gamma radiation and its applications in improvement of horsegram, in Feriz Adrovic (Ed.), Gamma Radiation, (Croatia: In Tech Publisher, 2012) 207-228.

[7] M. C. Kharkwal. Induced mutations in chickpea (Cicer arietinum L.) IV. Types of macro-mutations induced. Indian J. Genet., 60 (3), 2000, 305-320.

[8] P. M. Gaur and V. K. Gour. A gene inhibiting flower colour in chickpea (Cicer arietinum L.). Indian J. Genet., 62 (3), 2001, 273274 .

[9] R. Kartika and B. Subba Lakshmi. Effects of gamma-rays and EMS on two varieties of soybean. Asian J. Plant Sci., 5 (4), 2006, $721-724$.

[10] S. G. Auti and B. J. Apparao. Induced mutagenesis in mungbean (Vigna radiata (L.) Wilczek): Proc. Induced Plant Mutations in the Genomics Era. Food and Agricultural Organization of the United Nations. Italy, Rome, 2009, 107-110.

[11] A. A. Wani and M. Anis. Gamma rays induced bold seeded high yielding mutant in chickpea. Mutation Breeding Newsletter, 45, 2001, 20-21.

[12] S. Khan, M. R. Wani, M. Bhat and P. Kouser. Induction of morphological mutants in chickpea. International chickpea and pigeonpea newsletter, 6, 2004, 11 .

[13] J. D. Barshile and B. J. Apparao. Genetic improvement of chickpea (Cicer arietinum L.) using induced mutations: Proc. Induced Plant Mutations in the Genomics Era. Food and Agricultural Organization of the United Nations. Italy, Rome, 2009, $101-104$.

[14] E. Weber and W. Gottschalk. DieBeziehungen Zuischen Zellagrobe and internodienuange tri starhleindyzei earten Pisum mutant. Beitr Bio Pfl., 49, 1973, 101-126. 
[15] A. D. Blonstein and M. D. Gale. Cell size and cell number in dwarf barley and semidearf cereal mutants and their use in cross breeding II (Teidse 407). FAO/IAEA, Vienna., 1984, 19-29.

[16] N. B. Gaikawad. Genetic improvement of lentil (Lens culinaris Medik.) through mutagenesis. doctoral diss., Dr. Babasaheb Ambedkar Marathwada University, Aurangabad (MS), India, M. Sc., 2002.

[17] I. S. Solanki and B. Sharma. Morphological mutations induced by gamma rays, ethylene imine and N-Nitroso-N-Ethyl Urea in lentil. J. Nuclear Agric. Biol., 32 (1), 2003, 29-38.

[18] A. Kumar, M. N. Mishra and M. C. Kharkwal. Induced mutagenesis in blackgram (Vigna mungo (L.) Hepper). Indian J. Genet., 67 (1), 2007, 41-46

[19] J. G. Manjaya and R.S. Nandanwar. Genetic improvement of soybean variety JS 80-21 through induced mutations. Plant Mutation Reports, 1 (3), 2007, 36-40.

[20] S. G. Auti. Mutational Studies in mung (Vigna radiata (L.) Wilczek). doctoral diss., University of Pune, Pune (MS), India, M.Sc., 2005.

[21] D. D. Ahire. Isolation and characterization of induced mutants for morphological and agronomic traits and oil quality in soybean (Glycine max (L.) Merrill). doctoral diss., University of Pune, Pune (MS), India, M.Sc., 2008.

[22] A. V. Kothekar and V. S. Kothekar. Promissing mutants in moth bean. Marathwada University J. Sci., 19, 1992, 1-2.

[23] A. J. Deepalakshmi and A. Kumar. Frequency and spectrum of viable mutants in $\mathrm{M}_{2}$ generation of blackgram (Vigna mungo (L.) Hepper). Legume Res., 27 (3), 2004, 201-204.

[24] C. Vannirajan, P. Vivekanndan and J. Ramalingam. Spectrum and frequency of chlorophyll and viable mutations in $\mathrm{M}_{2}$ generation of Blackgram. Crop. Improv. 20 (2), 1993, 215-218.

[25] O. F. Adekola and F. Oluleye. Influence of mutation induction on the chemical composition of cowpea (Vigna unguiculata (L.) Walp). Afr. J. Biotechnol., 6 (18), 2007, 2143-2146.

[26] R. K. Mathur, P. Manivel, M. Y. Samdur and P. Paria. Girnar1 CLm-A new chemically induced curly leaf groundnut mutant. Indian J Genet., 61 (2), 2001, 196.

[27] P. A. Navale, P. N. Harer, W. S. Yadav and A.V. Tendulkar. Induced mutagenesis in rajmash bean. J. Maharashtra Agric. Univ., $22(2), 1997,244-245$.

[28] V. V. Dalvi. Gamma rays induced mutagenesis in horsegram (Macrotyloma uniflorum (Lam.) Verdc). M.Sc. (Agri) diss., Dr. B. S. K. K. Vidyapeeth, Dapoli (MS), India, M.Sc. (Agri), 1990.

[29] P. Rudraswami, K. P. Vishwanatha and C. Gireesh. Mutation studies in horsegram (Macrotyloma uniflorum (Lam.) Verdc). Proc. LSS-2006, BARC, Mumbai (MS), 2006, 88-89.

[30] I. S. Solanki. Isolation of macromutations and mutagenic effectiveness and efficiency in lentil. Indian J. Genet., 65 (4), 2005 , 264-268.

[31] S. R. Nawale. Studies on induced mutagenesis in cowpea (Vigna unguiculata (L.) Walp.) M.Sc. (Agri) diss., Dr. B. S. K. K. Vidyapeeth, Dapoli (MS) M.Sc. (Agri), 2004.

[32] J. D. Barshile. Studies on effect of mutagenesis employing EMS, SA and GR in Chickpea (Cicer arietinum L.). doctoral diss., University of Pune, Pune (MS), India, M.Sc., 2006.

[33] S. V. Sagade. Genetic improvement of urdbean (Vigna mungo L. Hepper) through mutation breeding. doctoral diss., University of Pune, Pune (MS), India, M.Sc., 2008.

[34] A. B. Tambe. Induction of genetic variability in Soybean (Glycine max (L.) Merrill) for yield contributing traits. doctoral diss., University of Pune, Pune (MS), India, M.Sc., 2009.

[35] W. Gottschalk and G. Wolff. The alteration of flowering and ripening times: Induced mutations in plant breeding: Proc. Springer Verlag. Berlin Heidelberg New York, Tokyo, 1983, 75-84

[36] P. Joshi and R. C. Verma. Radiation induced pod and seed mutants in Faba bean (Vicia faba L.). Indian J. Genet., 64 (2), 2004, $155-156$.

[37] M. Yaqoob and R. Abdur. Induced mutations studies in some mungbean (Vigna radiata L. Wilczek) cultivars. J. Biol Sci., 1 (9), 2001, 805-808.

[38] C. Beveridge and I. Murfet. The gigas mutant in pea is deficient in the floral stimulus. Physiol. Plant., 96, 1996, 637-645.

[39] A. H. Zakri and B. S. Jalani. Improvement of soybean through mutation breeding. Improvement of grain legume production using induced mutations: Research article, Proc. workshop Pullman Washington, USA, 1998, 451-461.

[40] V. P Singh and S. Agarwal. Induced high yielding mutants in cluster bean. Ind. J. Agric. Sci., 56 (10), 1986, 595-700.

[41] A. S. Sonawane. Genetic improvement of winged bean through mutation breeding. doctoral diss., Dr. B. A. M. U. Aurangabad (MS), India, M.Sc., 2000

[42] R. Sharma and V. P. Singh. The influence of altered moisture levels in seeds on the induction of mutations with EMS and gamma rays in mungbean. J. Ind. Bot. Soc., 71, 1992, 125-128.

[43] D. R. Gahlot, V. K. Vatsa and D. Kumar. Some mutants for pod and maturity characteristics in $\mathrm{M}_{2}$ generation of urdbean (Vigna mungo (L.) Hepper). Legume Res., 31 (4), 2008, 272-275.

[44] C. Toker and M. I. Cagirgan. Spectrum and frequency of induced mutations in chickpea. ICPN, 11, 2004, 8-10.

[45] N. Senapati, R. C. Misra and K. C. Muduli. Induced macromutations in blackgram (Vigna mungo (L.) Hepper). Legume Res., 31 (4), 2008, 243-248.

[46] B. S. Tyagi, P. K. Gupta. Induced macro-mutations in lentil. LENS Newsl, 18 (1), 1991, 37.

[47] S. K. Tripathy and D. Lenka. Identification and isolation of high yielding mutants in grasspea (Lathyrus sativus L.). www.arccjournals.com, abstracts, 33 (2), 2010, 134 
Effect of Mutagens on Frequency and Spectrum of Viable Mutations in Horsegram (Macrotyloma

Table 1: Effect of gamma radiation on frequency and spectrum of viable mutations in $\mathrm{M}_{2}$ generation of horsegram cv. Dapoli Kulthi-1.

\begin{tabular}{|c|c|c|c|c|c|c|c|c|}
\hline \multirow{2}{*}{ Mutants } & \multicolumn{8}{|c|}{ Gamma rays (Gy) } \\
\hline & \multirow{2}{*}{\multicolumn{2}{|c|}{$\frac{100}{1560}$}} & \multirow{2}{*}{\multicolumn{2}{|c|}{$\frac{200}{1710}$}} & \multirow{2}{*}{\multicolumn{2}{|c|}{$\frac{300}{1675}$}} & \multicolumn{2}{|r|}{400} \\
\hline \multirow{2}{*}{$\begin{array}{l}\text { Total plants } \\
\text { studied }\end{array}$} & & & & & & & & 1632 \\
\hline & No. & $\%$ & No. & $\%$ & No. & $\%$ & No. & $\%$ \\
\hline \multicolumn{9}{|l|}{ Plant habit } \\
\hline Gigas & 2.00 & $0.13 \pm 0.01$ & 5.00 & $0.29 \pm 0.02$ & 2.00 & $0.12 \pm 0.01$ & 0.00 & $0.00 \pm 0.00$ \\
\hline Tall & 2.00 & $0.13 \pm 0.01$ & 0.00 & $0.00 \pm 0.00$ & 3.00 & $0.18 \pm 0.01$ & 0.00 & $0.00 \pm 0.00$ \\
\hline Dwarf & 2.00 & $0.13 \pm 0.01$ & 2.00 & $0.12 \pm 0.01$ & 1.00 & $0.06 \pm 0.00$ & 1.00 & $0.06 \pm 0.00$ \\
\hline Compact & 2.00 & $0.13 \pm 0.01$ & 1.00 & $0.06 \pm 0.00$ & 2.00 & $0.12 \pm 0.01$ & 1.00 & $0.06 \pm 0.00$ \\
\hline Bouquet & 0.00 & $0.00 \pm 0.00$ & 0.00 & $0.00 \pm 0.00$ & 0.00 & $0.00 \pm 0.00$ & 0.00 & $0.00 \pm 0.00$ \\
\hline Erect & 2.00 & $0.13 \pm 0.00$ & 0.00 & $0.00 \pm 0.00$ & 1.00 & $0.06 \pm 0.00$ & 0.00 & $0.00 \pm 0.00$ \\
\hline Tendrilar & 0.00 & $0.00 \pm 0.00$ & 2.00 & $0.12 \pm 0.01$ & 0.00 & $0.00 \pm 0.00$ & 0.00 & $0.00 \pm 0.00$ \\
\hline Spreading & 2.00 & $0.13 \pm 0.01$ & 2.00 & $0.12 \pm 0.00$ & 1.00 & $0.06 \pm 0.00$ & 2.00 & $0.12 \pm 0.00$ \\
\hline Total & 12.00 & $0.77 \pm 0.04$ & 12.00 & $0.70 \pm 0.04$ & 10.00 & $0.60 \pm 0.03$ & 4.00 & $0.25 \pm 0.01$ \\
\hline \multicolumn{9}{|l|}{ Leaf } \\
\hline Supergigas & 0.00 & $0.00 \pm 0.00$ & 0.00 & $0.00 \pm 0.00$ & 0.00 & $0.00 \pm 0.00$ & 0.00 & $0.00 \pm 0.00$ \\
\hline Gigas & 2.00 & $0.13 \pm 0.01$ & 4.00 & $0.23 \pm 0.01$ & 2.00 & $0.12 \pm 0.01$ & 0.00 & $0.00 \pm 0.00$ \\
\hline Broad & 1.00 & $0.06 \pm 0.00$ & 0.00 & $0.00 \pm 0.00$ & 1.00 & $0.06 \pm 0.00$ & 0.00 & $0.00 \pm 0.00$ \\
\hline Narrow & 0.00 & $0.00 \pm 0.00$ & 2.00 & $0.12 \pm 0.00$ & 1.00 & $0.06 \pm 0.00$ & 0.00 & $0.00 \pm 0.00$ \\
\hline Small & 2.00 & $0.13 \pm 0.01$ & 1.00 & $0.06 \pm 0.00$ & 2.00 & $0.12 \pm 0.01$ & 0.00 & $0.00 \pm 0.00$ \\
\hline Tiny & 0.00 & $0.00 \pm 0.00$ & 0.00 & $0.00 \pm 0.00$ & 0.00 & $0.00 \pm 0.00$ & 0.00 & $0.00 \pm 0.00$ \\
\hline Stalked & 0.00 & $0.00 \pm 0.00$ & 0.00 & $0.00 \pm 0.00$ & 2.00 & $0.12 \pm 0.00$ & 1.00 & $0.06 \pm 0.00$ \\
\hline $\begin{array}{l}\text { Close } \\
\text { pinnae }\end{array}$ & 2.00 & $0.13 \pm 0.01$ & 0.00 & $0.00 \pm 0.00$ & 1.00 & $0.06 \pm 0.00$ & 0.00 & $0.00 \pm 0.00$ \\
\hline Curly & 1.00 & $0.06 \pm 0.00$ & 1.00 & $0.06 \pm 0.00$ & 2.00 & $0.12 \pm 0.01$ & 3.00 & $0.18 \pm 0.01$ \\
\hline Long & 0.00 & $0.00 \pm 0.00$ & 0.00 & $0.00 \pm 0.00$ & 0.00 & $0.00 \pm 0.00$ & 0.00 & $0.00 \pm 0.00$ \\
\hline Total & 8.00 & $0.51 \pm 0.02$ & 8.00 & \begin{tabular}{|l|}
$0.47 \pm 0.01$ \\
\end{tabular} & 11.00 & $0.66 \pm 0.02$ & 4.00 & $0.25 \pm 0.01$ \\
\hline \multicolumn{9}{|l|}{ Maturity } \\
\hline Early & 0.00 & $0.00 \pm 0.00$ & 0.00 & \begin{tabular}{|l|l|}
$0.00 \pm 0.00$ \\
\end{tabular} & 1.00 & $0.06 \pm 0.00$ & 0.00 & $0.00 \pm 0.00$ \\
\hline Late & 4.68 & $0.30 \pm 0.02$ & 3.42 & $0.20 \pm 0.01$ & 1.68 & $0.10 \pm 0.01$ & 0.00 & $0.00 \pm 0.00$ \\
\hline Total & 4.68 & $0.30 \pm 0.02$ & 3.42 & $0.20 \pm 0.01$ & 2.68 & $0.16 \pm 0.01$ & 0.00 & $0.00 \pm 0.00$ \\
\hline \multicolumn{9}{|l|}{ Pod } \\
\hline Gigas & 2.00 & $0.13 \pm 0.01$ & 4.00 & $0.23 \pm 0.01$ & 2.00 & $0.12 \pm 0.00$ & 0.00 & $0.00 \pm 0.00$ \\
\hline Long & 1.00 & $0.06 \pm 0.00$ & 0.00 & $0.00 \pm 0.00$ & 2.00 & $0.12 \pm 0.01$ & 0.00 & $0.00 \pm 0.00$ \\
\hline Broad & 1.00 & $0.06 \pm 0.00$ & 0.00 & $0.00 \pm 0.00$ & 0.00 & $0.00 \pm 0.00$ & 1.00 & $0.06 \pm 0.00$ \\
\hline Narrow & 3.00 & $0.19 \pm 0.01$ & 0.00 & $0.00 \pm 0.00$ & 2.00 & $0.12 \pm 0.00$ & 0.00 & $0.00 \pm 0.00$ \\
\hline Small & 2.00 & $0.13 \pm 0.01$ & 2.00 & $0.12 \pm 0.01$ & 2.00 & $0.12 \pm 0.01$ & 1.00 & $0.06 \pm 0.00$ \\
\hline Total & 9.00 & $0.58 \pm 0.02$ & 6.00 & $0.35 \pm 0.01$ & 8.00 & $0.48 \pm 0.01$ & 2.00 & $0.12 \pm 0.00$ \\
\hline $\begin{array}{l}\text { High } \\
\text { yielding }\end{array}$ & 0.00 & $0.00 \pm 0.00$ & 0.00 & $0.00 \pm 0.00$ & 2.00 & $0.12 \pm 0.01$ & 0.00 & $0.00 \pm 0.00$ \\
\hline Sterile & 0.00 & $0.00 \pm 0.00$ & 0.00 & $0.00 \pm 0.00$ & 0.00 & $0.00 \pm 0.00$ & 0.00 & $0.00 \pm 0.00$ \\
\hline Total freq. & & $2.16 \pm 0.10$ & & $1.72 \pm 0.09$ & & $1.99 \pm 0.09$ & & $0.61 \pm 0.03$ \\
\hline
\end{tabular}

Data are means of three replicates \pm standard deviation.

Table 2: Effect of EMS on frequency and spectrum of viable mutations in $\mathrm{M}_{2}$ generation of horsegram cv. Dapoli Kulthi-1.

\begin{tabular}{|c|c|c|c|c|c|c|c|c|}
\hline \multirow{2}{*}{ utants } & \multicolumn{8}{|c|}{ EMS (\%) } \\
\hline & \multirow{2}{*}{\multicolumn{2}{|c|}{$\frac{0.2}{1495}$}} & & 0.3 & & 0.4 & & 0.5 \\
\hline Total plants & & & \multicolumn{2}{|r|}{1495} & \multicolumn{2}{|r|}{1495} & \multicolumn{2}{|r|}{1495} \\
\hline studied & No. & $\%$ & No. & $\%$ & No. & $\%$ & No. & $\%$ \\
\hline \multicolumn{9}{|l|}{ Plant habit } \\
\hline Gigas & 3.00 & $0.20 \pm 0.01$ & 0.00 & $0.00 \pm 0.00$ & 0.00 & $0.00 \pm 0.00$ & 2.00 & $0.14 \pm 0.01$ \\
\hline Tall & 2.00 & $0.13 \pm 0.01$ & 0.00 & $0.00 \pm 0.00$ & 0.00 & $0.00 \pm 0.00$ & 3.00 & $0.21 \pm 0.01$ \\
\hline Dwarf & 1.00 & 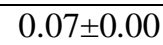 & 3.00 & \begin{tabular}{|l}
$0.21 \pm 0.01$ \\
\end{tabular} & 2.00 & $0.14 \pm 0.01$ & 1.00 & $0.07 \pm 0.00$ \\
\hline Compact & 2.00 & $0.13 \pm 0.01$ & 0.00 & $0.00 \pm 0.00$ & 0.00 & $0.00 \pm 0.00$ & 2.00 & $0.14 \pm 0.01$ \\
\hline Bouquet & 2.00 & $0.13 \pm 0.00$ & 0.00 & $0.00 \pm 0.00$ & 0.00 & $0.00 \pm 0.00$ & 1.00 & $0.07 \pm 0.00$ \\
\hline
\end{tabular}


Effect of Mutagens on Frequency and Spectrum of Viable Mutations in Horsegram (Macrotyloma

\begin{tabular}{|c|c|c|c|c|c|c|c|c|}
\hline Erect & 2.00 & $0.13 \pm 0.00$ & (20.00 & $0.00 \pm 0.00$ & "0.00 & $0.00 \pm 0.00$ & 1.00 & $0.07 \pm 0.00$ \\
\hline Tendrilar & 0.00 & $0.00 \pm 0.00$ & 1.00 & $0.07 \pm 0.00$ & 0.00 & $0.00 \pm 0.00$ & 0.00 & $0.00 \pm 0.00$ \\
\hline Spreading & 2.00 & $0.13 \pm 0.01$ & 0.00 & $0.00 \pm 0.00$ & 1.00 & $0.07 \pm 0.00$ & 1.00 & $0.07 \pm 0.00$ \\
\hline Total & 14.00 & $0.94 \pm 0.05$ & 4.00 & $0.27 \pm 0.01$ & 3.00 & $0.21 \pm 0.01$ & 11.00 & $0.78 \pm 0.04$ \\
\hline \multicolumn{9}{|l|}{ Leaf } \\
\hline Supergigas & 3.00 & $0.20 \pm 0.01$ & 4.00 & $0.27 \pm 0.01$ & 0.00 & $0.00 \pm 0.00$ & 0.00 & $0.00 \pm 0.00$ \\
\hline Gigas & 3.00 & $0.20 \pm 0.01$ & 0.00 & $0.00 \pm 0.00$ & 0.00 & $0.00 \pm 0.00$ & 2.00 & $0.14 \pm 0.01$ \\
\hline Broad & 1.00 & $0.07 \pm 0.00$ & 2.00 & $0.14 \pm 0.01$ & 0.00 & $0.00 \pm 0.00$ & 1.00 & $0.07 \pm 0.00$ \\
\hline Narrow & 3.00 & $0.20 \pm 0.01$ & 0.00 & $0.00 \pm 0.00$ & 1.00 & $0.07 \pm 0.00$ & 2.00 & $0.14 \pm 0.01$ \\
\hline Small & 2.00 & $0.13 \pm 0.01$ & 3.00 & $0.21 \pm 0.01$ & 0.00 & $0.00 \pm 0.00$ & 1.00 & $0.07 \pm 0.00$ \\
\hline Tiny & 0.00 & $0.00 \pm 0.00$ & 1.00 & $0.07 \pm 0.00$ & 0.00 & $0.00 \pm 0.00$ & 0.00 & $0.00 \pm 0.00$ \\
\hline Stalked & 0.00 & $0.00 \pm 0.00$ & 0.00 & $0.00 \pm 0.00$ & 0.00 & $0.00 \pm 0.00$ & 0.00 & $0.00 \pm 0.00$ \\
\hline $\begin{array}{l}\text { Close } \\
\text { pinnae }\end{array}$ & 1.00 & $0.07 \pm 0.00$ & 2.00 & $0.14 \pm 0.01$ & 0.00 & $0.00 \pm 0.00$ & 1.00 & $0.07 \pm 0.00$ \\
\hline Curly & 1.00 & $0.07 \pm 0.00$ & 2.00 & $0.14 \pm 0.01$ & 0.00 & $0.00 \pm 0.00$ & 0.00 & $0.00 \pm 0.00$ \\
\hline Long & 2.00 & $0.13 \pm 0.01$ & 1.00 & $0.07 \pm 0.00$ & 0.00 & $0.00 \pm 0.00$ & 1.00 & $0.07 \pm 0.00$ \\
\hline Total & 16.00 & $1.07 \pm 0.03$ & 15.00 & $1.03 \pm 0.03$ & 2.00 & $0.14 \pm 0.00$ & 8.00 & $0.57 \pm 0.02$ \\
\hline \multicolumn{9}{|l|}{ Maturity } \\
\hline Early & 2.00 & $0.13 \pm 0.01$ & 0.00 & $0.00 \pm 0.00$ & 0.00 & $0.00 \pm 0.00$ & 0.00 & $0.00 \pm 0.00$ \\
\hline Late & 1.50 & $0.10 \pm 0.01$ & 4.38 & $0.30 \pm 0.02$ & 0.00 & $0.00 \pm 0.00$ & 4.23 & $0.30 \pm 0.02$ \\
\hline Total & 3.50 & $0.23 \pm 0.01$ & 4.38 & $0.30 \pm 0.02$ & 0.00 & $0.00 \pm 0.00$ & 4.23 & $0.30 \pm 0.02$ \\
\hline \multicolumn{9}{|l|}{ Pod } \\
\hline Gigas & 3.00 & $0.20 \pm 0.01$ & 0.00 & $0.00 \pm 0.00$ & 0.00 & $0.00 \pm 0.00$ & 2.00 & $0.14 \pm 0.01$ \\
\hline Long & 2.00 & $0.13 \pm 0.01$ & 0.00 & $0.00 \pm 0.00$ & 0.00 & $0.00 \pm 0.00$ & 2.00 & $0.14 \pm 0.01$ \\
\hline Broad & 2.00 & $0.13 \pm 0.01$ & 0.00 & $0.00 \pm 0.00$ & 1.00 & $0.07 \pm 0.00$ & 2.00 & $0.14 \pm 0.01$ \\
\hline Narrow & 2.00 & $0.13 \pm 0.01$ & 0.00 & $0.00 \pm 0.00$ & 1.00 & $0.07 \pm 0.00$ & 2.00 & $0.14 \pm 0.01$ \\
\hline Small & 1.00 & $0.07 \pm 0.00$ & 0.00 & $0.00 \pm 0.00$ & 2.00 & $0.14 \pm 0.01$ & 1.00 & $0.07 \pm 0.00$ \\
\hline Total & 10.00 & $0.67 \pm 0.02$ & 0.00 & $0.00 \pm 0.00$ & 4.00 & $0.28 \pm 0.01$ & 9.00 & $0.64 \pm 0.02$ \\
\hline $\begin{array}{l}\text { High } \\
\text { yielding }\end{array}$ & 1.00 & $0.07 \pm 0.00$ & 0.00 & $0.00 \pm 0.00$ & 0.00 & $0.00 \pm 0.00$ & 0.00 & $0.00 \pm 0.00$ \\
\hline Sterile & 0.00 & $0.00 \pm 0.00$ & 0.00 & $0.00 \pm 0.00$ & 0.00 & $0.00 \pm 0.00$ & 2.00 & $0.14 \pm 0.01$ \\
\hline Total freq. & & $2.98 \pm 0.05$ & & $1.60 \pm 0.08$ & & $0.62 \pm 0.03$ & & $2.42 \pm 0.11$ \\
\hline
\end{tabular}

Data are means of three replicates \pm standard deviation.

Table 3a: Effect of gamma radiation and EMS on frequency and spectrum of viable mutations in $\mathrm{M}_{2}$ generation of horsegram cv. Dapoli Kulthi-1.

\begin{tabular}{|c|c|c|c|c|c|c|c|c|}
\hline \multirow{2}{*}{ Mutants } & \multicolumn{8}{|c|}{ Gamma Rays + EMS (\%) } \\
\hline & \multicolumn{2}{|c|}{$100+0.2$} & \multicolumn{2}{|c|}{$100+0.3$} & \multirow{2}{*}{\multicolumn{2}{|c|}{$\begin{array}{c}100+0.4 \\
1579\end{array}$}} & \multicolumn{2}{|c|}{$100+0.5$} \\
\hline \multirow{2}{*}{$\begin{array}{l}\text { Total plants } \\
\text { studied }\end{array}$} & \multicolumn{2}{|c|}{1579} & \multicolumn{2}{|r|}{1579} & & & \multicolumn{2}{|r|}{1579} \\
\hline & No. & $\%$ & No. & $\%$ & 1579 & $\%$ & No. & $\%$ \\
\hline \multicolumn{9}{|l|}{ Plant habit } \\
\hline Gigas & 1.00 & $0.06 \pm 0.00$ & 3.03 & $0.19 \pm 0.01$ & 0.00 & $0.00 \pm 0.00$ & 1.01 & $0.07 \pm 0.00$ \\
\hline Tall & 1.00 & $0.06 \pm 0.00$ & 0.00 & $0.00 \pm 0.00$ & 0.00 & $0.00 \pm 0.00$ & 0.00 & $0.00 \pm 0.00$ \\
\hline Dwarf & 2.00 & $0.13 \pm 0.01$ & 1.01 & $0.06 \pm 0.00$ & 1.01 & $0.07 \pm 0.00$ & 2.02 & $0.13 \pm 0.01$ \\
\hline Compact & 0.00 & $0.00 \pm 0.00$ & 2.02 & $0.13 \pm 0.01$ & 2.02 & $0.13 \pm 0.01$ & 1.01 & $0.07 \pm 0.00$ \\
\hline Bouquet & 1.00 & $0.06 \pm 0.00$ & 0.00 & $0.00 \pm 0.00$ & 0.00 & $0.00 \pm 0.00$ & 1.01 & $0.07 \pm 0.00$ \\
\hline Erect & 3.00 & $0.19 \pm 0.01$ & 0.00 & $0.00 \pm 0.00$ & 0.00 & $0.00 \pm 0.00$ & 0.00 & $0.00 \pm 0.00$ \\
\hline Tendrilar & 0.00 & $0.00 \pm 0.00$ & 0.00 & $0.00 \pm 0.00$ & 0.00 & $0.00 \pm 0.00$ & 0.00 & $0.00 \pm 0.00$ \\
\hline Spreading & 1.00 & $0.06 \pm 0.00$ & 0.00 & $0.00 \pm 0.00$ & 2.03 & $0.13 \pm 0.01$ & 0.00 & $0.00 \pm 0.00$ \\
\hline Total & 9.00 & $0.57 \pm 0.03$ & 6.07 & $0.39 \pm 0.02$ & 5.06 & $0.33 \pm 0.02$ & 5.06 & $0.33 \pm 0.02$ \\
\hline \multicolumn{9}{|l|}{ Leaf } \\
\hline Supergigas & 2.00 & $0.13 \pm 0.00$ & 0.00 & $0.00 \pm 0.00$ & 0.00 & $0.00 \pm 0.00$ & 0.00 & $0.00 \pm 0.00$ \\
\hline Gigas & 1.00 & $0.06 \pm 0.00$ & 3.00 & $0.19 \pm 0.01$ & 0.00 & $0.00 \pm 0.00$ & 3.00 & $0.20 \pm 0.01$ \\
\hline Broad & 0.00 & $0.00 \pm 0.00$ & 0.00 & $0.00 \pm 0.00$ & 0.00 & $0.00 \pm 0.00$ & 1.00 & $0.07 \pm 0.00$ \\
\hline Narrow & 1.00 & $0.06 \pm 0.00$ & 0.00 & $0.00 \pm 0.00$ & 0.00 & $0.00 \pm 0.00$ & 1.00 & $0.07 \pm 0.00$ \\
\hline Small & 2.00 & $0.13 \pm 0.01$ & 0.00 & $0.00 \pm 0.00$ & 0.00 & $0.00 \pm 0.00$ & 0.00 & $0.00 \pm 0.00$ \\
\hline Tiny & 0.00 & $0.00 \pm 0.00$ & 0.00 & $0.00 \pm 0.00$ & 1.00 & $0.07 \pm 0.00$ & 0.00 & $0.00 \pm 0.00$ \\
\hline Stalked & 0.00 & $0.00 \pm 0.00$ & 0.00 & $0.00 \pm 0.00$ & 0.00 & $0.00 \pm 0.00$ & 0.00 & $0.00 \pm 0.00$ \\
\hline
\end{tabular}


Effect of Mutagens on Frequency and Spectrum of Viable Mutations in Horsegram (Macrotyloma

\begin{tabular}{|l|l|l|l|l|l|l|l|l|}
\hline $\begin{array}{l}\text { Close } \\
\text { pinnae }\end{array}$ & 2.00 & $0.13 \pm 0.01$ & 0.00 & $0.00 \pm 0.00$ & 1.00 & $0.07 \pm 0.00$ & 2.01 & $0.13 \pm 0.01$ \\
\hline Curly & 1.00 & $0.06 \pm 0.00$ & 0.00 & $0.00 \pm 0.00$ & 0.00 & $0.00 \pm 0.00$ & 0.00 & $0.00 \pm 0.00$ \\
\hline Long & 1.00 & $0.06 \pm 0.00$ & 0.00 & $0.00 \pm 0.00$ & 0.00 & $0.00 \pm 0.00$ & 0.00 & $0.00 \pm 0.00$ \\
\hline Total & 10.00 & $0.63 \pm 0.02$ & 3.00 & $0.19 \pm 0.01$ & 2.01 & $0.13 \pm 0.00$ & 7.01 & $0.46 \pm 0.01$ \\
\hline Maturity \\
\hline Early & 0.00 & $0.00 \pm 0.00$ & 0.00 & $0.00 \pm 0.00$ & 0.00 & $0.00 \pm 0.00$ & 0.00 & $0.00 \pm 0.00$ \\
\hline Late & 3.16 & $0.20 \pm 0.01$ & 1.58 & $0.10 \pm 0.01$ & 0.00 & $0.00 \pm 0.00$ & 1.54 & $0.10 \pm 0.01$ \\
\hline Total & 3.16 & $0.20 \pm 0.01$ & 1.58 & $0.10 \pm 0.01$ & 0.00 & $0.00 \pm 0.00$ & 1.54 & $0.10 \pm 0.01$ \\
\hline Pod & \multicolumn{7}{|l|}{$\mid$} \\
\hline Gigas & 1.00 & $0.06 \pm 0.00$ & 3.06 & $0.19 \pm 0.01$ & 0.00 & $0.00 \pm 0.00$ & 3.06 & $0.20 \pm 0.01$ \\
\hline Long & 0.00 & $0.00 \pm 0.00$ & 0.00 & $0.00 \pm 0.00$ & 0.00 & $0.00 \pm 0.00$ & 0.00 & $0.00 \pm 0.00$ \\
\hline Broad & 0.00 & $0.00 \pm 0.00$ & 2.04 & $0.13 \pm 0.01$ & 0.00 & $0.00 \pm 0.00$ & 0.00 & $0.00 \pm 0.00$ \\
\hline Narrow & 0.00 & $0.00 \pm 0.00$ & 0.00 & $0.00 \pm 0.00$ & 0.00 & $0.00 \pm 0.00$ & 0.00 & $0.00 \pm 0.00$ \\
\hline Small & 2.00 & $0.13 \pm 0.01$ & 0.00 & $0.00 \pm 0.00$ & 1.02 & $0.07 \pm 0.00$ & 1.02 & $0.07 \pm 0.00$ \\
\hline Total & 3.00 & $0.19 \pm 0.01$ & 5.10 & $0.32 \pm 0.01$ & 1.02 & $0.07 \pm 0.00$ & 4.08 & $0.26 \pm 0.01$ \\
\hline $\begin{array}{l}\text { High } \\
\text { yielding }\end{array}$ & 0.00 & $0.00 \pm 0.00$ & 0.00 & $0.00 \pm 0.00$ & 0.00 & $0.00 \pm 0.00$ & 0.00 & $0.00 \pm 0.00$ \\
\hline Sterile & 2.00 & $0.13 \pm 0.01$ & 0.00 & $0.00 \pm 0.00$ & 0.00 & $0.00 \pm 0.00$ & 0.00 & $0.00 \pm 0.00$ \\
\hline Total freq. & & $1.72 \pm 0.08$ & & $1.00 \pm 0.05$ & & $0.52 \pm 0.03$ & & $1.16 \pm 0.06$ \\
\hline
\end{tabular}

Data are means of three replicates \pm standard deviation.

Table 3b: Effect of gamma radiation and EMS on frequency and spectrum of viable mutations in $\mathrm{M}_{2}$ generation of horsegram cv. Dapoli Kulthi-1.

\begin{tabular}{|c|c|c|c|c|c|c|c|c|}
\hline \multirow{2}{*}{ Mutants } & \multicolumn{8}{|c|}{ Gamma Rays + EMS (\%) } \\
\hline & \multicolumn{2}{|c|}{$200+0.2$} & \multirow{2}{*}{\multicolumn{2}{|c|}{$\begin{array}{c}200+0.3 \\
1472\end{array}$}} & \multirow{2}{*}{\multicolumn{2}{|c|}{$\frac{200+0.4}{1472}$}} & \multicolumn{2}{|c|}{$200+0.5$} \\
\hline \multirow{2}{*}{$\begin{array}{l}\text { Total plants } \\
\text { studied }\end{array}$} & \multicolumn{2}{|r|}{1472} & & & & & \multicolumn{2}{|r|}{1472} \\
\hline & No. & $\%$ & No. & $\%$ & No. & $\%$ & No. & $\%$ \\
\hline \multicolumn{9}{|l|}{ Plant habit } \\
\hline Gigas & 0.00 & $0.00 \pm 0.00$ & 0.00 & $0.00 \pm 0.00$ & \begin{tabular}{|l|}
0.00 \\
\end{tabular} & $0.00 \pm 0.00$ & 1.01 & $0.07 \pm 0.00$ \\
\hline Tall & 0.00 & $0.00 \pm 0.00$ & 0.00 & $0.00 \pm 0.00$ & 0.00 & $0.00 \pm 0.00$ & 1.01 & $0.07 \pm 0.00$ \\
\hline Dwarf & 0.00 & $0.00 \pm 0.00$ & 1.01 & $0.07 \pm 0.00$ & 2.03 & $0.14 \pm 0.01$ & 1.01 & $0.07 \pm 0.00$ \\
\hline Compac & 2.03 & $0.14 \pm 0.01$ & 0.00 & $0.00 \pm 0.00$ & 0.00 & $0.00 \pm 0.00$ & 1.01 & $0.07 \pm 0.00$ \\
\hline Bouquet & 2.02 & $0.14 \pm 0.00$ & 0.00 & $0.00 \pm 0.00$ & 0.00 & $0.00 \pm 0.00$ & 0.00 & $0.00 \pm 0.00$ \\
\hline Erect & 0.00 & $0.00 \pm 0.00$ & 0.00 & $0.00 \pm 0.00$ & \begin{tabular}{|l|}
0.00 \\
\end{tabular} & $0.00 \pm 0.00$ & 1.02 & $0.07 \pm 0.00$ \\
\hline Tendrilar & 1.01 & $0.07 \pm 0.00$ & 0.00 & $0.00 \pm 0.00$ & 0.00 & $0.00 \pm 0.00$ & 0.00 & $0.00 \pm 0.00$ \\
\hline Spreading & 1.01 & $0.07 \pm 0.00$ & 0.00 & $0.00 \pm 0.00$ & 2.03 & $0.14 \pm 0.01$ & 1.01 & $0.07 \pm 0.00$ \\
\hline Total & 6.08 & $0.41 \pm 0.02$ & 1.01 & $0.07 \pm 0.00$ & 4.05 & $0.28 \pm 0.01$ & 6.08 & $0.43 \pm 0.02$ \\
\hline \multicolumn{9}{|l|}{ Leaf } \\
\hline Supergigas & 0.00 & $0.00 \pm 0.00$ & 0.00 & $0.00 \pm 0.00$ & \begin{tabular}{|l|l|}
0.00 \\
\end{tabular} & $0.00 \pm 0.00$ & 0.00 & $0.00 \pm 0.00$ \\
\hline Gigas & 0.00 & $0.00 \pm 0.00$ & 0.00 & $0.00 \pm 0.00$ & \begin{tabular}{|l|}
0.00 \\
\end{tabular} & $0.00 \pm 0.00$ & 1.00 & $0.07 \pm 0.00$ \\
\hline Broad & 1.00 & $0.07 \pm 0.00$ & 0.00 & $0.00 \pm 0.00$ & 0.00 & $0.00 \pm 0.00$ & 1.00 & $0.07 \pm 0.00$ \\
\hline Narrow & 0.00 & $0.00 \pm 0.00$ & 0.00 & $0.00 \pm 0.00$ & 0.00 & $0.00 \pm 0.00$ & 1.00 & $0.07 \pm 0.00$ \\
\hline Small & 2.01 & $0.14 \pm 0.01$ & 0.00 & $0.00 \pm 0.00$ & 1.00 & $0.07 \pm 0.00$ & 0.00 & $0.00 \pm 0.00$ \\
\hline Tiny & 1.00 & $0.07 \pm 0.00$ & 0.00 & $0.00 \pm 0.00$ & 0.00 & $0.00 \pm 0.00$ & 0.00 & $0.00 \pm 0.00$ \\
\hline Stalked & 0.00 & $0.00 \pm 0.00$ & 0.00 & $0.00 \pm 0.00$ & 0.00 & $0.00 \pm 0.00$ & 0.00 & $0.00 \pm 0.00$ \\
\hline $\begin{array}{l}\text { Close } \\
\text { pinnae }\end{array}$ & 1.00 & $0.07 \pm 0.00$ & 0.00 & 0.00 & 0.00 & $0.00 \pm 0.00$ & 0.00 & $0.00 \pm 0.00$ \\
\hline Curly & 1.01 & $0.07 \pm 0.00$ & 0.00 & $0.00 \pm 0.00$ & 0.00 & $0.00 \pm 0.00$ & 0.00 & $0.00 \pm 0.00$ \\
\hline Long & 0.00 & $0.00 \pm 0.00$ & 1.01 & $0.07 \pm 0.00$ & 0.00 & $0.00 \pm 0.00$ & 1.01 & $0.07 \pm 0.00$ \\
\hline Total & 6.02 & $0.41 \pm 0.01$ & 1.01 & $0.07 \pm 0.00$ & 1.00 & $0.07 \pm 0.00$ & 4.01 & $0.29 \pm 0.01$ \\
\hline \multicolumn{9}{|l|}{ Maturity } \\
\hline Early & 2.04 & $0.14 \pm 0.01$ & 0.00 & $0.00 \pm 0.00$ & \begin{tabular}{|l|}
0.00 \\
\end{tabular} & $0.00 \pm 0.00$ & 0.00 & $0.00 \pm 0.00$ \\
\hline Late & 0.00 & $0.00 \pm 0.00$ & 0.00 & $0.00 \pm 0.00$ & 2.04 & $0.14 \pm 0.01$ & 0.00 & $0.00 \pm 0.00$ \\
\hline Total & 2.04 & $0.14 \pm 0.01$ & 0.00 & $0.00 \pm 0.00$ & 2.04 & $0.14 \pm 0.01$ & 0.00 & $0.00 \pm 0.00$ \\
\hline \multicolumn{9}{|l|}{ Pod } \\
\hline Gigas & 0.00 & $0.00 \pm 0.00$ & 0.00 & $0.00 \pm 0.00$ & \begin{tabular}{|l|}
0.00 \\
\end{tabular} & $0.00 \pm 0.00$ & 1.02 & $0.07 \pm 0.00$ \\
\hline Long & 1.02 & $0.07 \pm 0.00$ & 0.00 & $0.00 \pm 0.00$ & \begin{tabular}{|l|}
0.00 \\
\end{tabular} & $0.00 \pm 0.00$ & 0.00 & $0.00 \pm 0.00$ \\
\hline
\end{tabular}


Effect of Mutagens on Frequency and Spectrum of Viable Mutations in Horsegram (Macrotyloma

\begin{tabular}{|l|l|l|l|l|l|l|l|l|}
\hline Broad & 0.00 & $0.00 \pm 0.00$ & 0.00 & $0.00 \pm 0.00$ & 0.00 & $0.00 \pm 0.00$ & 0.00 & $0.00 \pm 0.00$ \\
\hline Narrow & 0.00 & $0.00 \pm 0.00$ & 0.00 & $0.00 \pm 0.00$ & 0.00 & $0.00 \pm 0.00$ & 0.00 & $0.00 \pm 0.00$ \\
\hline Small & 0.00 & $0.00 \pm 0.00$ & 1.02 & $0.07 \pm 0.00$ & 2.05 & $0.14 \pm 0.01$ & 0.00 & $0.00 \pm 0.00$ \\
\hline Total & 1.02 & $0.07 \pm 0.00$ & 1.02 & $0.07 \pm 0.00$ & 2.05 & $0.14 \pm 0.00$ & 1.02 & $0.07 \pm 0.00$ \\
\hline $\begin{array}{l}\text { High } \\
\text { yielding }\end{array}$ & 0.00 & $0.00 \pm 0.00$ & 0.00 & $0.00 \pm 0.00$ & 0.00 & $0.00 \pm 0.00$ & 0.00 & $0.00 \pm 0.00$ \\
\hline Sterile & 0.00 & $0.00 \pm 0.00$ & 0.00 & $0.00 \pm 0.00$ & 0.00 & $0.00 \pm 0.00$ & 0.00 & $0.00 \pm 0.00$ \\
\hline Total freq. & & $1.02 \pm 0.05$ & & $0.21 \pm 0.01$ & & $0.63 \pm 0.03$ & & $0.78 \pm 0.04$ \\
\hline
\end{tabular}

Data are means of three replicates \pm standard deviation.

Table 3c: Effect of gamma radiation and EMS on frequency and spectrum of viable mutations in $\mathrm{M}_{2}$ generation of horsegram cv. Dapoli Kulthi-1.

\begin{tabular}{|c|c|c|c|c|c|c|c|c|}
\hline \multirow{2}{*}{ Mutants } & \multicolumn{8}{|c|}{ Gamma Rays + EMS (\%) } \\
\hline & \multicolumn{2}{|c|}{$300+0.2$} & \multirow{2}{*}{\multicolumn{2}{|c|}{$\frac{300+0.3}{1510}$}} & \multirow{2}{*}{\multicolumn{2}{|c|}{$\frac{300+0.4}{1510}$}} & \multicolumn{2}{|c|}{$300+0.5$} \\
\hline \multirow{2}{*}{$\begin{array}{l}\text { Total plants } \\
\text { studied }\end{array}$} & \multicolumn{2}{|c|}{1510} & & & & & \multicolumn{2}{|c|}{1510} \\
\hline & No. & $\%$ & $\%$ & $\%$ & \multicolumn{2}{|c|}{$\%$} & No. & $\%$ \\
\hline \multicolumn{9}{|l|}{ Plant habit } \\
\hline Gigas & 2.00 & $0.13 \pm 0.01$ & 0.00 & $0.00 \pm 0.00$ & 0.00 & $0.00 \pm 0.00$ & 1.01 & $0.07 \pm 0.00$ \\
\hline Tall & 1.00 & $0.07 \pm 0.00$ & 0.00 & $0.00 \pm 0.00$ & 0.00 & $0.00 \pm 0.00$ & 1.01 & $0.07 \pm 0.00$ \\
\hline Dwarf & 2.00 & $0.13 \pm 0.01$ & 1.01 & $0.07 \pm 0.00$ & 1.01 & $0.07 \pm 0.00$ & 1.01 & $0.07 \pm 0.00$ \\
\hline Compact & 1.00 & $0.07 \pm 0.00$ & 1.01 & $0.07 \pm 0.00$ & 0.00 & $0.00 \pm 0.00$ & 1.01 & $0.07 \pm 0.00$ \\
\hline Bouquet & 0.00 & $0.00 \pm 0.00$ & 0.00 & $0.00 \pm 0.00$ & 0.00 & $0.00 \pm 0.00$ & 0.00 & $0.00 \pm 0.00$ \\
\hline Erect & 1.00 & $0.07 \pm 0.00$ & 0.00 & $0.00 \pm 0.00$ & 0.00 & $0.00 \pm 0.00$ & 0.00 & $0.00 \pm 0.00$ \\
\hline Tendrilar & 1.00 & $0.07 \pm 0.00$ & 0.00 & $0.00 \pm 0.00$ & 0.00 & $0.00 \pm 0.00$ & 2.03 & $0.14 \pm 0.01$ \\
\hline Spreading & 1.00 & $0.07 \pm 0.00$ & 2.03 & $0.13 \pm 0.01$ & 0.00 & $0.00 \pm 0.00$ & 0.00 & $0.00 \pm 0.00$ \\
\hline Total & 9.00 & $0.60 \pm 0.03$ & 4.05 & $0.27 \pm 0.01$ & 1.01 & $0.07 \pm 0.00$ & 6.08 & $0.42 \pm 0.02$ \\
\hline \multicolumn{9}{|l|}{ Leaf } \\
\hline Supergigas & 0.00 & $0.00 \pm 0.00$ & 0.00 & $0.00 \pm 0.00$ & 0.00 & $0.00 \pm 0.00$ & 1.00 & $0.07 \pm 0.00$ \\
\hline Gigas & 2.00 & $0.13 \pm 0.01$ & 0.00 & $0.00 \pm 0.00$ & 0.00 & $0.00 \pm 0.00$ & 1.00 & $0.07 \pm 0.00$ \\
\hline Broad & 1.00 & $0.07 \pm 0.00$ & 0.00 & $0.00 \pm 0.00$ & 0.00 & $0.00 \pm 0.00$ & 1.00 & $0.07 \pm 0.00$ \\
\hline Narrow & 0.00 & $0.00 \pm 0.00$ & 0.00 & $0.00 \pm 0.00$ & 1.00 & $0.07 \pm 0.00$ & 0.00 & $0.00 \pm 0.00$ \\
\hline Small & 3.00 & $0.20 \pm 0.01$ & 0.00 & $0.00 \pm 0.00$ & \begin{tabular}{|l|}
0.00 \\
\end{tabular} & $0.00 \pm 0.00$ & \begin{tabular}{|l|}
2.01 \\
\end{tabular} & $0.14 \pm 0.01$ \\
\hline Tiny & 0.00 & $0.00 \pm 0.00$ & 0.00 & $0.00 \pm 0.00$ & 0.00 & $0.00 \pm 0.00$ & 0.00 & $0.00 \pm 0.00$ \\
\hline Stalked & 0.00 & $0.00 \pm 0.00$ & 0.00 & $0.00 \pm 0.00$ & 0.00 & $0.00 \pm 0.00$ & \begin{tabular}{|l|}
0.00 \\
\end{tabular} & $0.00 \pm 0.00$ \\
\hline $\begin{array}{l}\text { Close } \\
\text { pinnae }\end{array}$ & 0.00 & 0. & 2.01 & $=0.01$ & 0.00 & $0.00 \pm 0.00$ & 0.00 & $0.00 \pm 0.00$ \\
\hline Curly & 0.00 & $0.00 \pm 0.00$ & 0.00 & $0.00 \pm 0.00$ & 1.01 & $0.07 \pm 0.00$ & 0.00 & $0.00 \pm 0.00$ \\
\hline Long & 0.00 & $0.00 \pm 0.00$ & 0.00 & $0.00 \pm 0.00$ & 0.00 & $0.00 \pm 0.00$ & \begin{tabular}{|l|}
0.00 \\
\end{tabular} & $0.00 \pm 0.00$ \\
\hline Total & 6.00 & $0.40 \pm 0.01$ & 2.01 & $0.13 \pm 0.00$ & 2.01 & $0.14 \pm 0.00$ & 5.01 & $0.35 \pm 0.01$ \\
\hline \multicolumn{9}{|l|}{ Maturity } \\
\hline Early & 1.00 & 0.070 .00 & 0.00 & $0.00 \pm 0.00$ & 0.00 & $0.00 \pm 0.00$ & 0.00 & $0.00 \pm 0.00$ \\
\hline Late & 2.00 & $0.13 \pm 0.01$ & 0.00 & $0.00 \pm 0.00$ & 0.00 & $0.00 \pm 0.00$ & 1.02 & $0.07 \pm 0.00$ \\
\hline Total & 3.00 & $0.20 \pm 0.01$ & 0.00 & $0.00 \pm 0.00$ & \begin{tabular}{|l|}
0.00 \\
\end{tabular} & \begin{tabular}{|l|l}
$0.00 \pm 0.00$ \\
\end{tabular} & 1.02 & $0.07 \pm 0.00$ \\
\hline \multicolumn{9}{|l|}{ Pod } \\
\hline Gigas & 2.00 & $0.13 \pm 0.01$ & 0.00 & $0.00 \pm 0.00$ & \begin{tabular}{|l|}
0.00 \\
\end{tabular} & $0.00 \pm 0.00$ & \begin{tabular}{|l|}
1.02 \\
\end{tabular} & $0.07 \pm 0.00$ \\
\hline Long & 0.00 & $0.00 \pm 0.00$ & 1.02 & $0.07 \pm 0.00$ & 0.00 & $0.00 \pm 0.00$ & 0.00 & $0.00 \pm 0.00$ \\
\hline Broad & 1.00 & $0.07 \pm 0.00$ & 0.00 & $0.00 \pm 0.00$ & 0.00 & $0.00 \pm 0.00$ & 2.04 & $0.14 \pm 0.01$ \\
\hline Narrow & 0.00 & $0.00 \pm 0.00$ & 2.04 & $0.13 \pm 0.01$ & 0.00 & $0.00 \pm 0.00$ & 1.02 & $0.07 \pm 0.00$ \\
\hline Small & 1.00 & $0.07 \pm 0.00$ & 1.02 & $0.07 \pm 0.00$ & 0.00 & $0.00 \pm 0.00$ & 3.07 & $0.21 \pm 0.01$ \\
\hline Total & 4.00 & $0.26 \pm 0.01$ & 4.08 & $0.27 \pm 0.01$ & 0.00 & $0.00 \pm 0.00$ & 7.15 & $0.49 \pm 0.01$ \\
\hline $\begin{array}{l}\text { High } \\
\text { yielding }\end{array}$ & 0.00 & 0.0 & 0.00 & 0 & 0.00 & 0.0 & 0.00 & 0.1 \\
\hline Sterile & 0.00 & $0.00 \pm 0.00$ & 0.00 & $0.00 \pm 0.00$ & \begin{tabular}{|l|l|}
0.00 \\
\end{tabular} & $0.00 \pm 0.00$ & 0.00 & $0.00 \pm 0.00$ \\
\hline Total freq. & & $1.46 \pm 0.07$ & & $0.67 \pm 0.03$ & & $0.21 \pm 0.01$ & & $1.32 \pm 0.07$ \\
\hline
\end{tabular}

Data are means of three replicates \pm standard deviation. 
Effect of Mutagens on Frequency and Spectrum of Viable Mutations in Horsegram (Macrotyloma

Table 3d: Effect of gamma radiation and EMS on frequency and spectrum of viable mutations in $\mathrm{M}_{2}$ generation of horsegram cv. Dapoli Kulthi-1.

\begin{tabular}{|c|c|c|c|c|c|c|c|c|}
\hline \multirow{2}{*}{ Mutants } & \multicolumn{8}{|c|}{ Gamma Rays + EMS (\%) } \\
\hline & \multirow{2}{*}{\multicolumn{2}{|c|}{$\frac{400+0.2}{1489}$}} & & & \multirow{2}{*}{\multicolumn{2}{|c|}{$\frac{400+0.4}{1489}$}} & \multicolumn{2}{|c|}{$400+0.5$} \\
\hline \multirow{2}{*}{$\begin{array}{l}\text { Total plants } \\
\text { studied }\end{array}$} & & & \multicolumn{2}{|c|}{ PUTO.5 } & & & & 1489 \\
\hline & No. & $\%$ & No. & $\%$ & No. & $\%$ & No. & $\%$ \\
\hline \multicolumn{9}{|l|}{ Plant habit } \\
\hline Gigas & 3.03 & $0.20 \pm 0.01$ & 0.00 & $0.00 \pm 0.00$ & 1.01 & $0.07 \pm 0.00$ & 2.02 & $0.14 \pm 0.01$ \\
\hline Tall & 0.00 & $0.00 \pm 0.00$ & 0.00 & $0.00 \pm 0.00$ & 1.01 & $0.07 \pm 0.00$ & 1.01 & $0.07 \pm 0.00$ \\
\hline Dwarf & 2.02 & $0.13 \pm 0.01$ & 1.01 & $0.07 \pm 0.00$ & 4.05 & $0.28 \pm 0.02$ & 3.04 & $0.21 \pm 0.01$ \\
\hline Compact & 1.01 & $0.07 \pm 0.00$ & 0.00 & $0.00 \pm 0.00$ & 1.01 & $0.07 \pm 0.00$ & 0.00 & $0.00 \pm 0.00$ \\
\hline Bouquet & 0.00 & $0.00 \pm 0.00$ & 0.00 & $0.00 \pm 0.00$ & 0.00 & $0.00 \pm 0.00$ & 0.00 & $0.00 \pm 0.00$ \\
\hline Erect & 0.00 & $0.00 \pm 0.00$ & 0.00 & $0.00 \pm 0.00$ & 2.03 & $0.14 \pm 0.00$ & 2.03 & $0.14 \pm 0.00$ \\
\hline Tendrilar & 1.01 & $0.07 \pm 0.00$ & 0.00 & $0.00 \pm 0.00$ & 0.00 & $0.00 \pm 0.00$ & 2.03 & $0.14 \pm 0.01$ \\
\hline Spreading & 1.01 & $0.07 \pm 0.00$ & 0.00 & $0.00 \pm 0.00$ & 2.03 & $0.14 \pm 0.01$ & 0.00 & $0.00 \pm 0.00$ \\
\hline Total & 8.10 & $0.54 \pm 0.03$ & 1.01 & $0.07 \pm 0.00$ & 11.15 & $0.76 \pm 0.04$ & 10.13 & $0.70 \pm 0.04$ \\
\hline \multicolumn{9}{|l|}{ Leaf } \\
\hline Supergigas & 0.00 & $0.00 \pm 0.00$ & 0.00 & $0.00 \pm 0.00$ & 0.00 & $0.00 \pm 0.00$ & 0.00 & $0.00 \pm 0.00$ \\
\hline Gigas & 3.00 & $0.20 \pm 0.01$ & 0.00 & $0.00 \pm 0.00$ & 1.00 & $0.07 \pm 0.00$ & 2.00 & $0.14 \pm 0.01$ \\
\hline Broad & 0.00 & $0.00 \pm 0.00$ & 0.00 & $0.00 \pm 0.00$ & 0.00 & $0.00 \pm 0.00$ & 0.00 & $0.00 \pm 0.00$ \\
\hline Narrow & 1.00 & $0.07 \pm 0.00$ & 0.00 & $0.00 \pm 0.00$ & 0.00 & $0.00 \pm 0.00$ & 0.00 & $0.00 \pm 0.00$ \\
\hline Small & 1.00 & $0.07 \pm 0.00$ & 0.00 & $0.00 \pm 0.00$ & 4.01 & $0.28 \pm 0.01$ & 3.01 & $0.21 \pm 0.01$ \\
\hline Tiny & 0.00 & $0.00 \pm 0.00$ & 1.00 & $0.07 \pm 0.00$ & \begin{tabular}{|l|}
0.00 \\
\end{tabular} & $0.00 \pm 0.00$ & 0.00 & $0.00 \pm 0.00$ \\
\hline Stalked & 0.00 & $0.00 \pm 0.00$ & 0.00 & $0.00 \pm 0.00$ & \begin{tabular}{|l|}
0.00 \\
\end{tabular} & $0.00 \pm 0.00$ & 0.00 & $0.00 \pm 0.00$ \\
\hline $\begin{array}{l}\text { Close } \\
\text { pinnae }\end{array}$ & 1.00 & $0.07 \pm 0.00$ & 0.00 & $0.00 \pm 0.00$ & 2.01 & 0.1 & 0.00 & $0.00 \pm 0.00$ \\
\hline Curly & 1.01 & $0.07 \pm 0.00$ & 0.00 & $0.00 \pm 0.00$ & \begin{tabular}{|l|}
0.00 \\
\end{tabular} & $0.00 \pm 0.00$ & 0.00 & $0.00 \pm 0.00$ \\
\hline Long & 0.00 & $0.00 \pm 0.00$ & 0.00 & $0.00 \pm 0.00$ & 1.01 & $0.07 \pm 0.00$ & 2.02 & $0.14 \pm 0.01$ \\
\hline Total & 7.02 & $0.47 \pm 0.01$ & 1.00 & $0.07 \pm 0.00$ & \begin{tabular}{|l|}
8.03 \\
\end{tabular} & $0.56 \pm 0.02$ & 7.03 & $0.49 \pm 0.01$ \\
\hline \multicolumn{9}{|l|}{ Maturity } \\
\hline Early & 0.00 & $0.00 \pm 0.00$ & 0.00 & $0.00 \pm 0.00$ & 3.05 & $0.21 \pm 0.01$ & 4.07 & $0.28 \pm 0.02$ \\
\hline Late & 2.03 & $0.13 \pm 0.01$ & 0.00 & $0.00 \pm 0.00$ & 0.00 & $0.00 \pm 0.00$ & 0.00 & $0.00 \pm 0.00$ \\
\hline Total & 2.03 & $0.13 \pm 0.01$ & 0.00 & $0.00 \pm 0.00$ & 3.05 & $0.21 \pm 0.01$ & 4.07 & $0.28 \pm 0.01$ \\
\hline \multicolumn{9}{|l|}{ Pod } \\
\hline Gigas & 2.04 & $0.13 \pm 0.01$ & 0.00 & $0.00 \pm 0.00$ & \begin{tabular}{|l|}
1.02 \\
\end{tabular} & $0.07 \pm 0.00$ & 1.02 & $0.07 \pm 0.00$ \\
\hline Long & 0.00 & $0.00 \pm 0.00$ & 0.00 & $0.00 \pm 0.00$ & 1.02 & $0.07 \pm 0.00$ & 1.02 & $0.07 \pm 0.00$ \\
\hline Broad & 0.00 & $0.00 \pm 0.00$ & 0.00 & $0.00 \pm 0.00$ & \begin{tabular}{|l|}
0.00 \\
\end{tabular} & $0.00 \pm 0.00$ & 0.00 & $0.00 \pm 0.00$ \\
\hline Narrow & 3.06 & $0.20 \pm 0.01$ & 4.08 & $0.27 \pm 0.01$ & 0.00 & $0.00 \pm 0.00$ & 0.00 & $0.00 \pm 0.00$ \\
\hline Small & 1.02 & $0.07 \pm 0.00$ & 0.00 & $0.00 \pm 0.00$ & 2.04 & $0.14 \pm 0.01$ & 2.04 & $0.14 \pm 0.01$ \\
\hline Total & 6.12 & $0.40 \pm 0.01$ & 4.08 & $0.27 \pm 0.01$ & 4.08 & $0.28 \pm 0.01$ & 4.08 & $0.28 \pm 0.01$ \\
\hline $\begin{array}{l}\text { High } \\
\text { yielding }\end{array}$ & 0.00 & $0.00 \pm 0.00$ & 0.00 & $0.00 \pm 0.00$ & 0.00 & $0.00 \pm 0.00$ & 0.00 & $0.00 \pm 0.00$ \\
\hline Sterile & 0.00 & $0.00 \pm 0.00$ & 0.00 & $0.00 \pm 0.00$ & 0.00 & $0.00 \pm 0.00$ & 0.00 & $0.00 \pm 0.00$ \\
\hline Total freq. & & $1.54 \pm 0.08$ & & $0.41 \pm 0.02$ & & $1.81 \pm 0.09$ & & $1.75 \pm 0.09$ \\
\hline
\end{tabular}

Data are means of three replicates \pm standard deviation. 